\title{
Resistance of Olive Cultivars to the Defoliating Pathotype of Verticillium dahliae
}

\author{
Consuelo Martos-Moreno, Francisco Javier López-Escudero ${ }^{1}$, \\ and Miguel Ángel Blanco-López \\ Departamento de Agronomiá, Universidad de Córdoba, Campus Universitario \\ de Rabanales, Edificio Celestino Mutis (C4), 14071, Córdoba, Spain
}

Additional index words. Verticillium wilt, root-dip inoculation, rootstocks, olive germplasm bank

\begin{abstract}
The resistance of 33 major olive cultivars to Verticillium dahliae was assessed in four experiments conducted under controlled conditions. Nine-month-old nursery olive plants were inoculated with a defoliating isolate (V117) of $V$. dahliae. Resistance was evaluated by assessing symptom severity using a $0-4$ rating scale and estimating the area under disease progress curves with reference to the maximum value potentially reached over the assessment period (AUDPCP). The percentage of plants killed and that of plants that recovered from the disease were used as additional parameters for classifying the cultivars. Twenty-six of the 33 cultivars were found to be susceptible or extremely susceptible to the defoliating $V$. dahliae isolate. They exhibited values for AUDPCP higher than $45 \%$ with mortality higher than $37.5 \%$. A second group of cultivars, which included 'Cipresino', 'Koroneiki', 'Oblonga', and 'Sevillenca', were classified as moderately resistant because they showed an important reduction of the final mean severity values and of values for AUDPCP that ranged from $23 \%$ to $42 \%$. 'Changlot Real', 'Empeltre', and 'Frantoio' were resistant to the defoliating isolate of $V$. dahliae. The resistance of 'Empeltre' and 'Frantoio', although previously reported, was consistently confirmed, because the two cultivars exhibited no dead plants and had very low values for AUDPCP and final disease. This is the first report of resistance of 'Changlot Real' to Verticillium wilt based on ability of the plants to recover from infection and the absence of dead plants. These three cultivars will be useful for inclusion in Verticillium wiltbreeding programs.
\end{abstract}

Spain is the leading world producer of olive oil and table olives. The most important olive-growing area of Spain is Andalucía where olive orchards cover more than 1.5 million ha of a total 2.4 millions ha in Spain (Barranco et al., 1996). Verticillium wilt of olive, incited by Verticillium dahliae, is the most important disease in olive orchards in Spain, and it is very common in the irrigated zones around the Guadalquivir Valley as well as in intensive plantations throughout all of the Mediterranean basin (Al-Ahmad and Mosli, 1993; López-Escudero and BlancoLópez, 2001; Serrhini and Zeroual, 1995; Tjamos and Jiménez-Díaz, 1998). The main

\footnotetext{
Received for publication 5 Jan. 2006. Accepted for publication 5 Apr. 2006. This research was supported by a bursary for Ms. Martos-Moreno from the Ministerio de Ciencia y Tecnología, Spain, and funded by projects AGF-97-0546 from the Comisión Interministerial de Ciencia y Tecnología, Spain, and QLRT-1999-1523 from the European Commission. We thank J. M. Caballero Reig and C. del Río for supplying plant material from the World Olive Germplasm Bank (Centro de Investigación y Formación Agraria "Alameda del Obispo," IFAPA, Junta de Andalucía, Córdoba, Spain).

${ }^{1}$ To whom correspondence should be addressed;
} e-mail ag2loesj@uco.es. olive cultivated area. Unfortunately, these three cultivars are extremely susceptible to the defoliating pathotype of $V$. dahliae and susceptible ('Picual' and 'Hojiblanca') or extremely susceptible ('Cornicabra') to the nondefoliating one (López-Escudero et al., 2004). The wide variability of olive cultivars, most of which are local varieties selected by growers over hundreds of years, may provide an important genetic resource for resistance to Verticillium wilt. The purpose of this work was to continue to screen olive cultivars from the germplasm bank with a view to examining their response to the defoliating pathotype of $V$. dahliae. Resistance to this strain would also ensure resistance to other less virulent isolates, as previously shown by López-Escudero et al. (2004).

\section{Materials and Methods}

\section{Plant material and fungus isolate}

Thirty-three olive cultivars were assessed for resistance to $V$. dahliae in four different experiments (I-IV) conducted under controlled conditions in a growth chamber using between 7 and 12 replicates per cultivar. The plant material consisted of 9-month-old rooted cuttings and was obtained from the World Olive Germplasm Bank of Centro de Investigación y Formación Agraria, 'Alameda del Obispo' (Córdoba, Spain). The cuttings were clones of each cultivar, coming from the same mother plant. Nineteen Spanish, three Greek, and four Italian cultivars, in addition to seven others from various olive growing countries, were studied (Table 1).

Plants were inoculated with isolate V117 of $V$. dahliae, a highly virulent cotton defoliating strain (Blanco-López et al., 1989) from the collection of the Plant Pathology Laboratory of the Agronomy Department, University of Cordoba. Two olive cultivars, 'Picual' (the major Spanish cultivar) and 'Oblonga' (from the United States), were used as references of known resistance in each experiment. 'Picual' is highly susceptible to isolate V117, whereas 'Oblonga' is moderately resistant to it (Hartman et al., 1971; López-Escudero et al., 2004; RodríguezJurado et al., 1993). A similar number of noninoculated controls plants of each cultivar was included in each experiment. on the use of resistant cultivars (BlancoLópez and Jiménez-Diaz, 1995; Hiemstra and Harris, 1998).

Efforts have focused on a resistance screening program started in 1994 and involving major Spanish and foreign cultivars from the olive world germplasm bank (Caballero and del Río, 2001) of IFAPA (CIFA 'Alameda del Obispo', Córdoba, Spain). The initial results suggested that cultivars Empeltre, Frantoio, and Oblonga might be useful in a breeding program or as rootstocks for grafting (López-Escudero et al., 2004).

Approximately 260 olive cultivars are grown in Spain, three of which ('Picual' and 'Hojiblanca' in Andalusia and 'Cornicabra' in the central region) account for half of the

\section{Plant inoculation}

The technique used to inoculate plants was based on Rodriguez-Jurado (1993) and validated in an extensive screening study on olive cultivars conducted by López-Escudero et al. (2004). The inoculum consisted of a distilled and sterilized water suspension of $10^{7}$ conidia/mL prepared from 6 -d-old singlespore cultures of fungus isolate V117 that were maintained on potato dextrose agar (PDA) slants at $4{ }^{\circ} \mathrm{C}$. Plants were inoculated by dipping their bare root systems in the suspension for 30 minutes, transplanted to sterile soil (1:1:1 peat:sand:lime) in pots, and incubated in a growth chamber maintained at $22 \pm 2{ }^{\circ} \mathrm{C}$ and $95 \% \mathrm{RH}$. Plants were 
Table 1. Values of disease parameters of olive cultivars inoculated with the defoliating isolate V117 of Verticillium dahliae ${ }^{\mathrm{z}}$.

\begin{tabular}{|c|c|c|c|c|c|}
\hline Cultivar & Reference $^{y}$ & Origin & AUDPCP ${ }^{x}$ & FMS $^{\mathrm{w}}$ & PDP $^{v}$ \\
\hline Callosina & CIFA (CM0 R40 F9 A13) & Spain & 75.9 & 4 & 100 \\
\hline Fulla de Salce & CIFA (CMI-II R674 F15 A19) & Spain & 75.1 & 3.4 & 71.4 \\
\hline Megaritiki & CIFA (CMV R108 F7 A17) & Greece & 68.5 & 3.7 & 50 \\
\hline Nabali & CIFA (CMV R158 F8 A5) & Israel & 67.6 & 4 & 100 \\
\hline Picual $^{u}$ & CIFA (seto) & Spain & 65.2 & 3.9 & 95.2 \\
\hline Negro del Carpio & CIFA (CMI-II R750 F9 A14 & Spain & 63.6 & 3.8 & 75 \\
\hline Gordal de Hellin & CIFA (CMV R567 F10 A9,10) & Spain & 62.3 & 3.9 & 75 \\
\hline Borriolenca & CIFA (CM0 R41 F9 A12) & Spain & 61.8 & 3.6 & 75 \\
\hline Carrasqueño Lucena & CIFA (CM0 R287 F15 A14) & Spain & 61.3 & 4 & 100 \\
\hline Chemlal de Kabilye & CIFA (CMV R118 F10 A13,14) & Argyle & 61 & 3.8 & 75 \\
\hline Manzanilla & Agromillora & Spain & 60.0 & 4 & 100 \\
\hline Manzanilla Cacereña & CIFA (CMIV R430 F5 A37) & Spain & 60.0 & 4 & 100 \\
\hline Zarza & CIFA (CMV R38 F6 A15) & Spain & 59.9 & 2.8 & 50 \\
\hline Morona & CIFA (CMV R270 F5 A7) & Spain & 59.2 & 4 & 100 \\
\hline Pendolino & CIFA (CM0 R87 F2 A14) & Italy & 59.2 & 3.5 & 87.5 \\
\hline Ascolana Tenera & CIFA (CMV R62 F7,9 A10) & Italy & 58.4 & 3.5 & 62.5 \\
\hline Bouteillan & CIFA (CM0 R63 F4 A13) & France & 57.8 & 3.9 & 87.5 \\
\hline Ayvalik & CIFA (CMV R97 F8,19 A20) & Turkey & 56.0 & 4 & 100 \\
\hline Nevadillo Blanco de Jaén & CIFA (CM0 R44 F10 A13) & Spain & 55.2 & 3.8 & 75 \\
\hline Dulzal de Carmona & CIFA (CMIV R31 F8 A9) & Spain & 54.2 & 3.9 & 87.5 \\
\hline Dokkar & CIFA (CMIV R539 F8 A29) & Turkey & 52.7 & 3.4 & 71.4 \\
\hline Imperial de Jaén & CIFA (CM0 R30 F6 A9) & Spain & 47.6 & 3.4 & 71.4 \\
\hline Arbequina & Agromillora & Spain & 47.3 & 3.6 & 75 \\
\hline Azapa & CIFA (CMI-II R726 F28 A2) & Chile & 46.8 & 3.1 & 62.5 \\
\hline Kalogerida & CIFA (CMI-II R691 F6 A9) & Greece & 45.9 & 3.2 & 42.8 \\
\hline Arbosana & Agromillora & Spain & 44.9 & 3.0 & 37.5 \\
\hline Cipresino & CIFA (CMV R90 F7 A1) & Italy & 42.1 & 1.8 & 12.5 \\
\hline Koroneiki & Agromillora & Greece & 38.2 & 1.4 & 25 \\
\hline Sevillenca & CIFA (CM0 R227 F14 A6) & Spain & 32.7 & 2.9 & 37.5 \\
\hline Oblonga $^{6}$ & CIFA (CMV R210 F8 A9,10) & USA & 23.6 & 1.2 & 13.3 \\
\hline Changlot Real & CIFA (CM0 R15 F14 A11) & Spain & 22.0 & 1.0 & 0 \\
\hline Empeltre & Agromillora & Spain & 14.7 & 0.9 & 0 \\
\hline Frantoio & Agromillora & Italy & 7.3 & 0.5 & 0 \\
\hline
\end{tabular}

${ }^{2}$ Nine-month-old olive plants were inoculated with a cotton-defoliating isolate of Verticillium dahliae. Symptom severity was assessed weekly from 2 to 12 weeks after inoculation.

'CIFA, Centro de Investigación y Formación Agraria 'Alameda del Obispo' (Córdoba, Spain); CMV World Olive Germplasm Bank; R, register number; F, row; A, tree.

${ }^{x}$ AUDPCP, area under the disease progress curve with reference to the maximum value potentially reached over the assessment period.

wFMS, final mean severity of symptoms 12 weeks after inoculation.

vPDP, percentage of dead plants.

'The values for the reference cultivars, 'Picual' and 'Oblonga' are the means of the AUDPCPs obtained in experiments II to IV and III and IV, respectively.

held in the dark for $3 \mathrm{~d}$ after inoculation to avoid shock and then light and humidity levels were adjusted to a photoperiod of $14 \mathrm{~h}\left(216 \mu \mathrm{Em}-2 \mathrm{~s}^{-1}\right.$ fluorescent light $)$ and $80 \% \mathrm{RH}$.

\section{Disease assessment}

Disease severity was evaluated on a weekly basis for 10 weeks starting 2 weeks after inoculation. Wilt resistance was assessed on a scale from $0-4$ based on the percentage of plant tissue that was affected by chlorosis, leaf and shoot necrosis, or defoliation $(0=$ healthy plant or plant without symptoms; $1=$ plant affected by $1 \%$ to $33 \%$; $2=34 \%$ to $66 \% ; 3=67 \%$ to $99 \% ; 4=$ dead plant). The percentage of dead plants (PDP), recovery from the disease (Hiemstra and Harris, 1998; López-Escudero and BlancoLópez, 2001; López-Escudero et al., 2004; Wilhelm and Taylor, 1965) and other symptoms such as marginal spots of leaves and irregular growth of twigs were also considered in estimating the severity of the reactions. The area under the disease progress curve (Campbell and Madden, 1990) for each cultivar was estimated with reference to the periments in which responses of 'Picual' or 'Oblonga' were statistically different, the AUDPCP values for cultivars used in such experiments were corrected for the percentage of the difference between the AUDPCP values for the reference cultivars in both significant and nonsignificant experiments. Statistical analyses were performed using Statistix 8.0 program (Analytical Software, Tallahassee, Fla). Mean values were compared by Fisher protected LSD at $P=0.05$.

\section{Classification of cultivars according to resistance}

The resistance of each olive cultivar to wilt was categorized according to the criteria of López-Escudero et al. (2004). Thus, cultivars were classified into resistance categories corresponding to the following AUDPCP ranges: highly resistant $(\mathrm{HR})=0 \%$ to $10 \%$; resistant $(\mathrm{R})=11 \%$ to $30 \%$; moderately resistant (MS) $=31 \%$ to $50 \%$; susceptible (S) $=51 \%$ to $70 \%$; and extremely susceptible (E) $=71 \%$ to $100 \%$. The final values for percentage dead plants (PDP) and the ability of plants to recover from infection, expressed in terms of the symptom remission during the test period (Hiemstra and Harris, 1998; López-Escudero and Blanco-López, 2001; López-Escudero and Blanco-López, 2005; Wilhelm and Taylor, 1965), were also considered for the final classification of a given cultivar.

\section{Results}

\section{Disease symptoms and virulence of isolates}

The most common symptoms observed were chlorosis, wilt, defoliation, drying of buds and stems, rolling and necrosis of leaves, and the absence of or a delay in stem growth. Noninoculated control plants exhibited none of these symptoms; they efficiently produced new buds and twigs after 4 or 5 weeks of growing in the chamber and exhibited normal stem growth.

Generalized chlorosis was one of the most frequent symptoms in the inoculated cultivars; occasionally, however, these spots became necrotic tissues as observed in 'Nevadillo Blanco de Jaén'. Some cultivars developed extensive chlorosis at the onset of leaf rolling and reproduced the syndrome of apoplexy (Blanco-López et al., 1984; LópezEscudero and Blanco-López, 2001). Chlorosis was the most frequent symptom in plants that exhibited the highest resistance at the end of the experiment such as 'Changlot Real', 'Empeltre', 'Frantoio', or 'Oblonga.'

Defoliation was the most frequent and severe symptom in almost every cultivar. It started at low or moderate levels 3 to 4 weeks after inoculation and increased with time. In some cultivars, severe defoliation appeared abruptly 4 to 5 weeks after inoculations leaving main stems with only a couple of leaves at their tips. Such was the case with 'Arbequina', 'Callosina', 'Manzanilla Cacereña', 'Morona', and 'Nabali'. Progressive defoliation was observed on weeks 7 to 8 after inoculation, 
when the residual leaves, still attached to the twigs, started to roll and dry.

Recovery from the disease, signaled by saturation or inflection points in the progress curves for symptom severity, was only observed in a few cultivars, namely 'Cipresino', 'Changlot Real', 'Empeltre', 'Frantoio', and 'Koroneiki' (Fig. 1).

\section{Disease progress and analysis of resistance}

Analyses of variance of AUDPCP for the reference cultivar 'Picual' revealed the absence of statistical differences between experiments except in the plants that were inoculated in experiment I. In this experiment, the AUDPCP reached $49.7 \%$ as compared with $65.1 \%$ (the same mean value of experiments II to IV that were statistically nonsignificant). On the other hand, the AUDPCPs for 'Oblonga' in experiments I and II were higher than the normal mean value observed when the cultivar was inoculated with isolate V117 in previous experiments (López-Escudero et al., 2004). Therefore, the final mean severity in experiments I and II was higher than 3.75 in both experiments, and mortality was $100 \%$ and $87.5 \%$, respectively. Techniques using RAPD molecular markers (Barranco et al., 2000) revealed that the 'Oblonga' plants used in experiments I and II were in fact a different cultivar. However, the amplification products (using primers OPA-19, OPC-11, OPD-05, OPX-01, and OPX-03) precluded the identification of the specific cultivar. This compelled us to exclude this reference cultivar from experiments I and II in comparing the responses of the other cultivars, so comparisons were based on the mean response of 'Oblonga' plants in experiments III and IV.

The $V$. dahliae defoliating isolate caused $70 \%$ to $100 \%$ mortality (PDP) in 20 of the 33 cultivars. These cultivars were classified as extremely susceptible to this highly virulent isolate (Table 2). All 'Ayvalik', 'Callosina', 'Carrasqueño de Lucena', 'Manzanilla Cacereña', 'Morona', and 'Navali' plants were killed. Mortality in these plants normally increased strongly 8 to 9 weeks after inoculation. 'Cipresino', 'Koroneiki', 'Oblonga', and 'Sevillenca' exhibited between $12.5 \%$ and $37.5 \%$ mortality, with AUDPCP values lower than $42 \%$, being catalogued as moderately susceptible cultivars. The former 2 cultivars showed also a good recovery level (Fig. 1). On the other hand, 'Changlot Real', 'Empeltre', and 'Frantoio' were considered as resistant, because these cultivars exhibited no dead plants and very low AUDPCP and final mean severity (FMS) values (Tables 1 and 2).

\section{Discussion}

Our method proved effective for assessing cultivar resistance to Verticillium wilt. The response to the disease exhibited by the reference cultivars, 'Picual' and 'Oblonga', were effectively distinguished in terms of the mean AUDPCP and PDP values; also, they
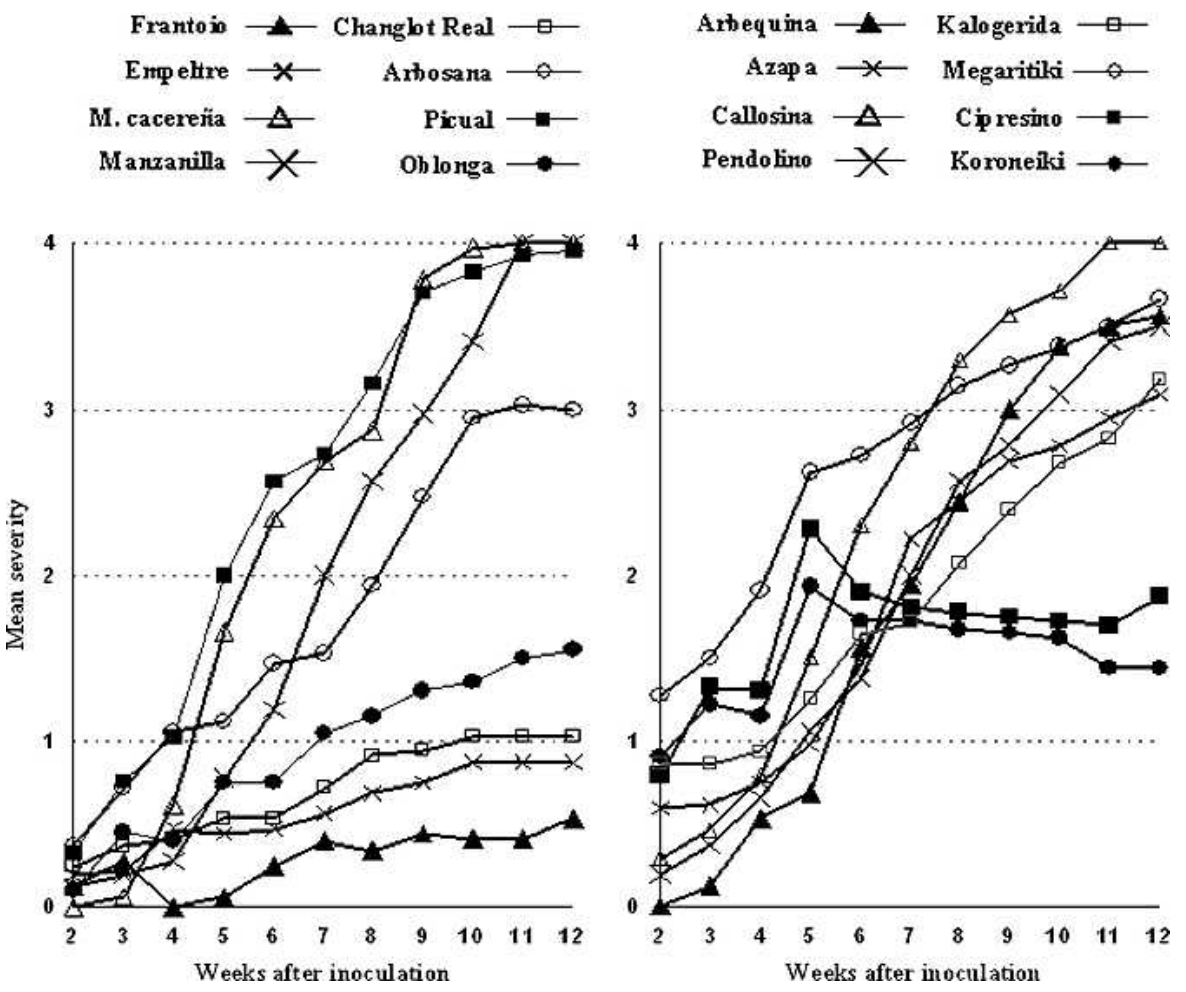

Fig. 1. Disease progress based on symptom severity of olive cultivars inoculated with defoliating isolate V117 of Verticillium dahliae. Assessment of wilt symptom severity was made for 12 weeks beginning 2 weeks after inoculation and based on a scale of $0-4$ according to percentage of plant tissue affected by necrosis of leaves and twigs, chlorosis, defoliation, or rolling of leaves $(0=$ healthy plant or plant with no symptoms; $1=1 \%$ to $33 \% ; 2=34 \%$ to $66 \% ; 3=67 \%$ to $99 \%$ and $4=$ dead plant). Mean values for symptom severity for cultivars 'Picual' and 'Oblonga' were from experiments II to IV and III and IV, respectively.

were consistent with previously reported values for infested fields (Martos-Moreno et al., 2001). All cultivars exhibited a high frequency of positive isolations of the pathogen from affected plant tissues during the experiments; therefore, plants became infected irrespective of their resistance as previously found by López-Escudero et al. (2004) and Rodríguez-Jurado (1993).

Twenty-six of the cultivars were classified as susceptible or extremely susceptible to the defoliating isolate of $V$. dahliae (Table 2). Twenty of them, including the reference cultivar 'Picual', were extremely susceptible, exhibiting high levels of the evaluated disease parameters (Tables 1 and 2). 'Arbequina'

reached AUDPCP value of up to $47.3 \%$, which is lower than the $72.2 \%$ reported by López-Escudero et al. (2004). This difference may be the result of the use of a different cultivar clone. However, 'Arbequina' was classified as extremely susceptible on the basis of its high final PDP value. The response of this cultivar to wilt, widely used in high-density orchards, seems to depend strongly on the inoculum potential of the pathogen and the genetic variability of the clones. Wilhelm (1981) and Wilhelm and Taylor (1965) obtained a clone called 'Allegra' from cultivar 'Arbequina' after several years of resistance assessment in artificial and field conditions. They characterized

Table 2. Resistance of olive cultivars to Verticillium wilt incited by the defoliating pathotype V117 of Verticillium dahliae.

\begin{tabular}{ll}
\hline Susceptibility & \\
\hline ES & Cultivars \\
& Arbequina, Ayvalik, Borriolenca, Bouteillan, Callosina \\
& Carrasqueño de Lucena, Chemlal de Kabilye, Dulzal de Carmona \\
& Fulla de Salce, Gordal de Hellin, Imperial de Jaén, Manzanilla, \\
& Manzanilla Cacereña, Megaritiki, Morona, Nabali, Pendolino \\
& Negro del Carpio, Nevadillo Blanco de Jaén, Picual \\
S & Arbosana, Ascolana Tenera, Azapa, Dokkar, Kalogerida \\
& Zarza \\
MS & Cipresino, Koroneiki, Oblonga, Sevillenca \\
R & Changlot Real, Empeltre, Frantoio \\
\hline
\end{tabular}

${ }^{\mathrm{z}} \mathrm{R}=$ resistant; MS, moderately susceptible; $\mathrm{S}$, susceptible; ES, extremely susceptible. Susceptibility was determined from the area under disease progress curve with reference to the maximum value potentially reached over the assessment period (AUDPCP), percentage of dead plants 12 weeks after inoculation, and other complementary criteria such as the shape of the disease progress curve and recovery from the disease. ${ }^{\mathrm{y}}$ Resistance categories correspond to the following ranges of AUDPCP for the defoliating isolate of $V$. dahliae: $\mathrm{HR}=0 \%$ to $10 \% ; \mathrm{R}=11 \%$ to $30 \% ; \mathrm{MS}=31 \%$ to $50 \% ; \mathrm{S}=51 \%$ to $70 \%$; $\mathrm{ES}=71 \%$ to $100 \%$. 
'Allegra' as having a high level of resistance to nondefoliating pathotypes. On the other hand, in controlled inoculations, López-Escudero et al. (2004) found 'Allegra' to be susceptible to both defoliating and nondefoliating isolates. Also, observations conducted under field conditions in various olive orchards in Spain revealed that 'Arbequina' exhibited a delay in symptom expression relative to 'Picual'. This was ascribed to low inoculum potentials of cotton nondefoliating pathotypes of $V$. dahliae rather than to true resistance (M.A. Blanco-López, University of Córdoba, Spain, unpublished data).

The Spanish cultivars 'Empeltre' and 'Changlot Real' are worth special note because of their low final mean values of disease severity of symptoms (FMS) and AUDPCP and also because none of the plants was killed. They were therefore classified as resistant to the defoliating pathotype of V. dahliae.

Our results show a higher level of resistance for 'Empeltre' than those previously reported by López-Escudero et al. (2004). This is because of the lower AUDPCP values reached by this cultivar in the current studies (14.7\%) as compared with the previous studies $(30.9 \%)$. This could be explained by the natural variability of the plant material or by the use of different clones. 'Empeltre' is the main olive cultivar in the Spanish communities of Aragón and Baleares, where it occupies approximately 70,000 ha. It is currently being planted in other areas where it is being used to renew whole zones or to replace plants killed by the wilt. On the other hand, this is the first reported evidence for resistance of 'Changlot Real' to Verticillium wilt. This cultivar had an AUDPCP of $22 \%$ after 12 weeks of infection by the defoliating isolate V117. Although these results must be confirmed in additional tests under field conditions, this cultivar may be a good candidate for replanting, use as rootstock, or as a source of resistance in breeding programs. 'Changlot Real' is used mainly in the provinces of Alicante and Valencia where it occupies 5000 ha. It is also grown in Andalucía and in some places in the provinces of Córdoba and Jaén. It adapts easily to unfavorable soil conditions, exhibits a medium blooming time, usually produces fruits in racemes, and features alternate bearing. It also is susceptible to frost injury, drought, and olive knot, but exhibits an early onset of production and high yields of quality olives.

'Koroneiki' (Greek) and 'Cipresino' (Italian) were among cultivars from other countries that exhibited moderate levels of resistance to the defoliating isolate. The reaction of 'Koroneiki' was classified as tolerant by Tjamos et al. (1985), who inoculated plants by spraying the root system, probably using a nondefoliating isolate. However, the results obtained by Paplomatas and Elena (2001), who injected conidial suspensions of a Greek cotton defoliating isolate into stems of 2year-old olive plants, are consistent with our observation that cultivar 'Koroneiki' is resistant to wilt. Similarly, Pennisi et al. (1993) deemed 'Cipresino' moderately resistant, but they failed to state the specific pathotype of the pathogen that they used in their inoculations.

Wilt resistance of 'Frantoio' and 'Oblonga' has widely been reported in previous works (Cirulli and Montemurro, 1976; Hartman et al., 1971; López-Escudero et al., 2004; Wilhelm and Taylor, 1965). However, molecular analysis (Barranco et al., 2000) recently revealed that the 2 are identical. The results of LópezEscudero et al. (2004) confirmed that cultivars 'Frantoio' and 'Oblonga' were similar in terms of the values of the disease-related parameters, AUDPCP and PDP, reached by the plants when inoculated with defoliating and nondefoliating isolates of $V$. dahliae. However, the 'Frantoio' cultivar clone used in this work had AUDPCP and PDP values of 7.3 and 0 , respectively; whereas these values were 40.3 and 12.5 , respectively, in the test done by López-Escudero et al. (2004). Finally, in the current study, the 'Frantoio' clone had higher resistance values (Table 1) than did the 'Oblonga' clone, which led us to include the former in the group of resistant cultivars (Table 2 ). This variability is surely a consequence of the variability between the two mother plants from which olive cuttings were obtained, which were previously labeled as 'Frantoio' and 'Oblonga', but actually were different clones of the same cultivar 'Frantoio' (= 'Oblonga').

\section{Literature Cited}

Al-Ahmad, M.A. and M.N. Mosli. 1993. Verticillium wilt of olive in Syria. EPPO Bull. 23:521529.

Barranco, D., R. Fernández-Escobar, and L. Rallo. 1996. El cultivo del olivo. Ediciones MundiPrensa, Madrid, Spain. 605 pp.

Barranco, D., I. Trujillo, and P. Rallo. 2000. Are 'Oblonga' and 'Frantoio' olives the same cultivar? HortScience 35:1323-1325.

Blanco-López, M.A., J. Bejarano-Alcázar, J.M. Melero-Vara, and R.M. Jiménez-Díaz. 1989. Current status of Verticillium wilt of cotton in southern Spain. Pathogen variation and population in soil. In: Tjamos, E.C. and C.H. Beckman (eds). Vascular Wilt Diseases of Plants NATO ASI Series H: Cell Biology, vol. 28 (pp. 123-132). Springer-Verlag, New York.

Blanco-López, M.A. and R.M. Jiménez-Díaz. 1995. Una propuesta de lucha integrada contra la verticilosis del olivo. Fruticultura Profesional. Especial Producción Integrada 70:52-58.

Blanco-López, M.A., R.M. Jiménez-Díaz, and J.M. Caballero. 1984. Symptomatology, incidence and distribution of Verticillium wilt of olive trees in Andalucía. Phytopathol. Mediterr. 23:1-8.

Caballero, J.M. and C. del Río. 2001. Métodos de multiplicación. In: Barranco, D., R. FernandezEscobar, and L. Rallo (eds.). El cultivo del olivo (pp. 90-117). Ediciones Mundi-Prensa. Madrid, Spain.

Campbell, C.L. and L.V. Madden. 1990. Introduction to plant disease epidemiology. John Wiley, New York. 532 pp.

Cirulli, M. and G. Montemurro. 1976. A comparation of pathogenic isolates of Verticillium dahliae and sources of resistance in olive Agric. Conspectus Sci. 39:469-476.

Hartman, H., W.C. Schnathorst, and J. Whysler. 1971. Oblonga, a clonal olive rootstock resistant to Verticillium wilt. Calif. Agr. 25:1315.

Hiemstra, J. and D. Harris. 1998. Compendium of Verticillium wilt in tree species. Ponsen \& Looijen, Wageningen, The Netherlands. $80 \mathrm{pp}$

López-Escudero, F.J. and M.A. Blanco-López. 2001. Effect of a single or double soil solarization to control Verticillium Wilt in established olive orchards in Spain. Plant Dis. 85:489-496.

López-Escudero, F.J. and M.A. Blanco-López. 2005. Recovery of young olive trees from Verticillium dahliae. Eur. J. Plant Pathol. 113: 367-375.

López-Escudero, F.J., C. del Río, J.M. Caballero, and M.A. Blanco-López. 2004. Evaluation of olive cultivars for resistance to Verticillium dahliae. Eur. J. Plant Pathol. 110:79-85.

Martos-Moreno, C., J.M. Caballero, C. del Río, and M.A. Blanco-López. 2001. Epidemiological behaviour of olive cultivars in orchards infested with mixtures of defoliating and non-defoliating isolates of Verticillium dahliae. Page 67 in: Proc. 8th Int. Verticillium Symp., Cordoba, Spain.

Paplomatas, E.J. and K. Elena. 2001. Reaction of Greek olive cultivars to the cotton defoliating strain of Verticillium dahliae. Page 51 in: Proc. 8th Int. Verticillium Symp., Córdoba, Spain.

Pennisi, A.M., S.O. Cacciola, G. Magnano di San Lio, and G. Perrotta. 1993. Evaluation of the susceptibility of olive cultivars to Verticillium wilt. EPPO Bull. 23:537-541.

Rodríguez-Jurado, D. 1993. Interacciones huesped-parasito en la marchitez del olivo (Olea europaea L.) inducida por Verticillium dahliae Kleb. Ph.D. Thesis, University of Córdoba, Spain. 324 pp.

Rodríguez-Jurado, D., M.A. Blanco-López, H.F. Rapoport, and R.M. Jiménez-Díaz. 1993. Present status of Verticillium wilt of olive in Andalucía (southern of Spain). EPPO Bull. 23:513-516.

Serrhini, M.N. and A. Zeroual. 1995. La Verticilosis del olivo en Marruecos. Olivae 58:58-61.

Tjamos, E.C. and R.M. Jiménez-Díaz. 1998. Management of disease. In: Hiemstra, J. and D. Harris (eds). Compendium of Verticillium Wilt in Tree Species (pp. 55-57). Ponsen \& Looijen, Wageningen, The Netherlands.

Tjamos, E.C., D.A. Biris, and C.C. Thanassoulopoulos. 1985. Resistance evaluation to Verticillium dahliae of olive rootstocks. 3rd National Phytopathological conference. Hellenic Phytopathological Society. Greece. pp. 18-19.

Wilhelm, S. 1981. Sources and genetics of Verticillium wilt resistance in major crops. Page 65 in: Proc. 3rd Int. Verticillium Symp., Bari, Italy.

Wilhelm, S. and J.B. Taylor. 1965. Control of Verticillium wilt in olive through natural recovery and resistance. Phytopathology 55: 310-316. 